\title{
A Study on Internet Industry Self-regulation in China and Its Implications for Child Protection in Cyberspace
}

The International Journal of Community and Social Development

$1-14$

(C) The Author(s) 2020 Reprints and permissions: in.sagepub.com/journals-permissions-india DOI: I O.I I 77/25 I6602620930944 journals.sagepub.com/home/cod

(S)SAGE

\author{
Mubarak A. R.'
}

\begin{abstract}
Self-regulation of the Internet industry has been a popular policy approach adopted by many countries. However, unlike self-regulation of more traditional industries, self-regulation of the Internet industry has been a challenging process due to the sheer volume of cyberspace and involvement of stakeholders located beyond any single country's jurisdiction. The industry has achieved limited success in self-regulation, specifically in the area of child protection in cyberspace. China has actively adopted a policy of Internet industry self-regulation and public supervision of the Internet industry, in order to remove online material that is not suitable for children. This article critically reviews China's pre-emptive government regulation and stern actions to regulate the Internet industry to monitor the material that the Internet industry allows through its network. Despite criticism of the Chinese government for its attempts to control freedom of expression through the Internet, this article argues that China has in its own unique ways managed to monitor the contents in cyberspace. There are many valuable lessons to be learnt from the Chinese experience. Studying the unique working relationship that has evolved between the Chinese government and the Internet industry may be beneficial in understanding the ways in which vulnerable population groups like children can be protected in cyberspace.
\end{abstract}

\section{Keywords}

Child protection, China, Internet, Internet industry self-regulation, local-level community and social development, social policy

\footnotetext{
' Division of Social Work and Social Policy, Faculty of Health and Medical Sciences, University of Western Australia, Perth, Western Australia.
}

\section{Corresponding author:}

Mubarak A. R., Division of Social Work and Social Policy, Faculty of Health and Medical Sciences, University of Western Australia, Perth WA6009, Western Australia.

E-mail: mubarak.rahamthaulla@uwa.edu.au 


\section{Introduction}

Protection of children in cyberspace has been a major challenge faced by the modern world. No jurisdiction in the world, including both developed and developing countries, is an exception to this trend because of the universal nature of the problem. Internet is a wide web of network, which contains a huge range of contents harmful to the psycho-social development of children (Vartanova, Tolokonnikova, \& Cherevko, 2014). Because of the age and level of maturity of the brain, children have difficulty in coping with the intense nature of some information available on the Internet, which is intended for adult audience. Livingstone, Haddon, Gorzig, and Olafsson (2011) summarised three aspects of the Internet, which potentially harm children one way or the other. The content found in the Internet, dangerous contacts Internet can create for children and online behaviours which can pose serious challenge to children's mental health are the three major threats Internet poses to child development. Because of the seriousness of this problem, the Internet industry has come under intense pressure from the governments all over the world to urgently develop mechanisms to monitor the Internet contents and protect children from the harms of contents not suitable for children.

The Internet industry was initially a self-regulated global network of institutions, driven by its educational and later global business priorities. Regulation of the Internet industry to ensure that the information available in cyberspace is suitable for children has been a widely contested topic since the evolution of the Internet (Budziewics-Guzlecka \& Drab-Kurowska, 2018). The world community is still in the process of finding a commonly agreed-upon policy due to the complex nature of this topic. The complexity arises mainly from the multi-layered nature of cyberspace, which has no national boundaries. Internet as a global system predominantly has three layers to it (Mueller, Mathiason, \& Klein, 2007). The first layer is a network of the globally connected physical infrastructure of electronic devices connected by cables and routers, which are jointly owned by the governments and businesses. The second layer consists of logical infrastructure guided by software delivering the contents to users, and the third layer consists of the contents, which are the prime concern of the world community interested in the welfare of children. According to the Organisation for Economic Cooperation and Development (OECD, 2012), three types of online contents put children at risk, namely illegal contents, ageinappropriate or harmful contents and advice given to children. Internet contents constantly drawing the attention of the policymakers worldwide include the materials such as sexual exploitation of children, cyberbullying, racism, hate speech, pornography, violence, advice to suicide, consumption of drug and alcohol, body image issues, etc. Countries around the world have attempted to formulate national policy frameworks to ensure that their children are not harmed by these inappropriate Internet contents. However, there seem to be inconsistencies in their approach, depending on the cultural and legal framework and the individual country's approach to freedom of speech. 
Due to the multi-layered nature of the Internet, any initiative to regulate the contents of the Internet involves dialogue between policymakers and the Internet industry, which is often influenced by a range of geopolitical and business interests. This scenario has resulted in a fragmented policy scenario wherein different jurisdictions in the world have evolved their own way of regulating the Internet industry, depending on the prevailing political conditions. In due course, the market forces and the governments have evolved regulatory systems referred to as co-regulatory or self-regulatory systems. Co-regulatory method involves Internet industry working closely with the government to regulate the Internet contents, and self-regulatory method involves Internet industry voluntarily participating by regulating itself to monitor the Internet contents (Marsden, 2011).

Due to the constantly changing Internet technological landscape and the potential of the Internet radically changing the public opinion, Internet industry regulation has come under intense scrutiny in recent years. There often seems to be a lack of clarity regarding which agency or agencies regulate the Internet industry. The Working Group on Internet Governance formed by the United Nations (UN) observed that Internet governance is a complex regime influenced by the simultaneously occurring intergovernmental, technical and market-led forces (United Nations, 2005). Self-regulation of the Internet industry has been popular, involving Internet industry regulating itself voluntarily, and many developed countries adopted this principle. However, self-regulation of the Internet industry has been far more challenging than self-regulation of more traditional industries due to the huge volume of cyberspace and the involvement of stakeholders located beyond any one country's jurisdiction. Further, selfregulation works well when major players in the industry actively participate, which creates a bandwagon effect, and all others in the industry take part. An issue with the Internet industry is that there are too many companies involved, ranging in size from very small to very large, which makes it difficult to identify who is taking the leading role in the self-regulation process (Lee, 2002). Another issue is that the Internet industry self-regulation requires Internet companies to create the human resources and technological capabilities to monitor the quality of information individual company's networks transmit to their end users. This has been a major challenge to self-regulation because the Internet industry has no profit incentive to comply with regulation, making it very difficult for small companies and non-profit-based companies to follow industry self-regulation. Furthermore, companies that do not follow self-regulation gain a cost advantage, thus leading to companies interested in self-regulation losing enthusiasm for it. Thus, the marketplace dictates self-regulation of the Internet industry to a high degree; economic reasons prevent companies from enthusiastically adopting industry self-regulation. Another challenge for the Internet industry is that consumers, who are expected to report non-compliance to the industry body, may not be able to detect it easily. By the time the non-compliance is reported, it is too late; the damage has already been done to the consumers.

Given the challenges inherent in regulating the Internet industry self-regulation, countries around the world have been trying to find a balanced approach to 
regulate the Internet industry. There seems to be a confusion among different countries of the world whether to follow the universal principle of freedom of speech while governing the Internet contents or to take an authoritarian approach and strictly regulate the Internet content through unilateral policymaking. Especially the countries with freedom of speech are in the crossroads. For example, the Australian government's policy decision regarding Internet industry self-regulation is not based on wider public consultation but utilises some of the qualitative feedback obtained through the public consultation process to try to justify its case to proceed with its own proposal on filtering Internet content (Leitch \& Warren, 2015). This is a typical example of the government taking the interests of specific population groups, like children, unilaterally, while governing the Internet space. In this process, the government may not be able to respect the democratic rights of the Internet industry because the industry's business interests need to be sacrificed for the betterment of children. There seems to be an inconsistency in the best approach to regulate the Internet contents to safeguard the safety of vulnerable population groups, namely children. For example, OECD (2012) reports a wide range of policy positions by world countries. Australia, Turkey and Japan passed special bills to enforce strict regulation on the Internet industry. These legislations require mandatory filtering of illegal contents by Internet service providers (ISPs). The UK created new governing bodies such as United Kingdom Council for Child Internet Safety to enforce child safety online. Turkey created a separate law enforcement body called Turkish Internet Regulation Department. Canada and the USA adopted an approach of encouraging parents to take control and the Internet industry to adopt voluntary self-regulation. Whereas, the European Union (EU) has adopted partially regulated environment wherein the Internet industry voluntarily regulates itself and the parents install Internet filters to safeguard their children's safety.

While the countries around the world are trying to find a suitable approach to regulate the Internet contents, China has adopted a unilateral approach of enforcing Internet industry self-regulation through its command and control style policy enforcements, requiring the Internet industry to strictly monitor the Internet space with heavy penalties for companies not following the legislation. China's strictly regulated Internet industry is a very well-known phenomenon. China has made no secret that the State strictly enforces its regulation of Internet industry using self-regulation of the Internet industry. China's policy highlights that the safety of children can be ensured through government's active engagement with the Internet industry to regulate it using strict enforcement principles (White Paper-The Internet in China, 2010). The Internet Society of China-ISC (2009), which is the Chinese Internet industry association has made a public pledge of self-regulation to uphold professional ethics within the Internet industry. Article 9 of the self-regulation pledge clearly states that if the ISP discovers information that is inconsistent with the law on its network, it will voluntarily remove it. Article 11 of this self-regulation pledge requires the Internet industry to make its best efforts to take effective measures to create a healthy and civilised environment for Internet usage and to assist the users, especially children to use the Internet healthily. 
The Chinese model of imposing self-regulation upon the Internet industry to safeguard the cyberspace for children has come under increasing scrutiny in recent years. Funnell (2019) observes that the Chinese philosophy of regulating Internet has divided the countries to choose between the Western approach or the Chinese approach of regulating the Internet industry. He argues that the growing popularity of the Chinese model is due to the governments of all persuasion hoping to impose greater restrictions on the Internet industry due to the concerns over increasing breaches of security and vulnerability of people. In addition, since the other models of regulating Internet contents have many inconsistencies, the Chinese model has gained more attention in recent years. Keeping this trend in view, this article will study the Chinese approach to Internet industry selfregulation and its implications on the safety of children online.

\section{Methodology}

Information for this article was collected through primary and secondary sources. Primary data were collected during the researcher's visit to the China's Internet Industry Association in Beijing. The researcher met with the representatives of China Internet Industry Association with an interpreter and collected qualitative information on the background of Internet Industry Association in China and the way it regulates itself as per the Chinese government's policies to ensure that the contents of the Internet are suitable for children. In addition, secondary data for the this article were collected through an intensive review of literature related to China's Internet industry self-regulation and its implications for the child safety in cyberspace. Qualitative analysis was undertaken.

\section{Results}

\section{Internet Society of China and Its Self-Regulation of Internet Contents}

China's first access to the Internet started on 20 April 1994 via 64k special line in Beijing's Zhongguancun District (White Paper-The Internet in China, 2010). China has since embraced Internet technology enthusiastically. The Chinese government considered the Internet an important tool to boost its modernisation of China policy. During 1997, China's Ninth Five-Year Plan listed the Internet as part of the state information infrastructure, and it set a goal of vigorously developing a modern Internet industry (White Paper-The Internet in China, 2010). During 2002, the Tenth Five-Year Plan included a Specialized Plan for Informationisation under National Economic and Social Development, which involved plans to launch Internet-based services such as e-government, develop a software industry and grow e-commerce. Since then, China has allocated huge budgets to build Internet infrastructure. Between 1997 and 2009, an estimated 4.3 trillion yuan $(100$ yuan $=$ US\$15) was invested in building a nationwide optical 
communications network with a total length of 8.267 million $\mathrm{km}$, including $840,000 \mathrm{~km}$ of long-distance optical cables. By the end of 2009, an estimated 99.3 per cent of Chinese towns and 91.5 per cent of Chinese rural areas had Internet access, and 96 per cent of Chinese towns had broadband connections.

When the Internet was newly introduced in China during the late 1990s, people started experimenting with it. They used it for a range of illegal activities like the distribution of inappropriate material with obscene content and infringement of copyright. In order to regulate the quality of contents in the Internet, the Chinese government passed the State Council Decree No. 195 in 1996 and since then passed a flood of legislations to regulate cyberspace during the early 2000s (Cheung, 2006). To regulate Internet use and help Chinese communities use it in healthy ways, the Chinese State Council issued the Measures on the Administration of Internet Information Services in the year 2000. These Measures stated that an ISP shall not produce, reproduce, post or disseminate illegal information, and it shall immediately discontinue the transmission of such information if it finds such information in the ISP's network (White Paper-The Internet in China, 2010). Further, the ISPs were required to post their terms of use at a prominent place on their website and warn online subscribers of their legal liabilities for disseminating unlawful information. The ISPs were considered liable for punishment because this law considered them parties who knowingly 'induced or assisted' Internet users to engage in misconduct. In a 2002 court case known as Ying \& Gao vs. Sinoi.com, the court held an ISP jointly liable for punishment, based on its finding that the platform facilitated the users' misconduct (Ying \& Gao, 2002). They found the operator of the system at fault in its supervision and management processes. In this case, the ISP was held responsible as a gatekeeper; they were held responsible for managing and checking their website, and supervising and managing the information that passed through their network.

During the mid-2000s, as the Internet use grew in China, more complex cases came to the attention of the Chinese government, which increased the liability of ISPs to monitor their network contents. In the famous Tianya case, the ISP of an online forum was held liable for a user's defamatory post (Li-Xian, 2008; Tao, 2014). The court's judgement argued that even though the ISP could not monitor millions of postings before disseminating them to the public, it could screen them as soon as they were visible and could remove unlawful postings expeditiously or take some technological measure to filter them. This case reminded ISPs in China of the strict liability laws and led to heightened minimum monitoring standards even though this might cause a burden on ISPs.

\section{China's Approach for Safety of Children in Cyberspace}

The Chinese government's approach to the Internet has been to use it as a medium of economic growth and prosperity, while keeping its social interaction component under close watch. It is argued that Confucianism has greatly influenced China's social policies on Internet use due to the country's culture and traditions, which aim to regulate the Internet industry using a centralised, bureaucratic and 
hierarchical model that emphasises national security (Lyombe, Kumar, \& Qingjiang, 2011). The White Paper on China's policies on Internet use clearly states that protection of minors is an important area, and the state shall take all appropriate measures to prevent minors from overindulging in the Internet and prohibit any organisation or individual from producing, selling or renting inappropriate materials containing pornography, violence, murder, terror, gambling or other contents which are harmful to minors (White Paper-The Internet in China, 2010). China's social policies on the protection of children in cyberspace make it clear that the Internet is playing an increasingly important role in child development, and that illegal and harmful online material like pornography is seriously damaging young people's physical and psychological health.

China's social policies encourage the development of Internet tools that are suitable for children and support research initiatives to protect children in cyberspace (Chui \& Jordan, 2018). The recently amended Minors Protection Law insists that families, schools and others working closely with children collaborate to protect children from Internet-based harm, to create a healthy Internet environment, and to benefit from the Internet's potential good (Pinghui, 2019). Also, the Chinese government has formulated policies to regulate children's access to the Internet. For example, strict licensing procedures are in force for Internet cafes and gaming centres, which are not allowed to operate within $200 \mathrm{~m}$ of schools. There are controls on these businesses' trading hours, and all computers manufactured in China have anti-addiction software installed (Tao, 2014). The Chinese government has also established media organisations such as the Network Film \& TV Centre of The Communication Centre of Chinese Communist Youth League of China (CCCYLC) (www.k618.com) and allocated human resources and funds to educate the Chinese community about safe Internet use.

\section{Discussion}

The Chinese government's policy of enforcing Internet industry self-regulation and assisting the industry in taking personal responsibility for the content it allows in cyberspace remains the core principle underlying China's policies for the protection of children in cyberspace. The ISC, as the body representing the Internet industry, adopted self-regulation of Internet content as a policy to protect the interests of Chinese citizens (Internet Society of China, 2009). Like every country in the world, China has created its unique business environment in line with its specific cultural and historical background. The Chinese government has played a proactive role in nurturing and protecting businesses operating in China, and in this process has gained control over resources that are crucial for business sustainability. Especially, this control is severe on politically sensitive businesses controlled by the Ministry of Posts and Telecommunications such as the ISPs. These businesses must survive under extreme pressure to work hard not only for technological supremacy but also to achieve social legitimation and recognition from the government, which has undue power over the telecommunications business sector in general (Low, 2010). In such circumstances, the ISC has the mandate to self-regulate the Internet industry to protect the interests of Chinese 
citizens, especially children who, as vulnerable members of society, require constant protection in cyberspace.

As a part of the Internet industry self-regulation, China pressures Chinese Internet companies and applications to enforce the censorship regulations stringently or risk suspensions, fines or even closure. Such pressure has intensified since the new cybersecurity law came into effect in June 2017 (Freedom on the Net, 2018). In 2017, China's popular social networking sites Tencent, Weibo and Baidu received heavy fines as a penalty for allowing users to post banned content such as pornography (Jing \& Chen, 2018). The Chinese government's ongoing pressure on social media companies has pressured these companies to hire more employees to monitor the content transmitted through their networks. For example, in 2017, Sina Weibo reportedly recruited 1,000 content supervisors (Global Voices, 2017). Similarly, in 2018, one of leading social media companies Jinri Toutiao reported that it was hiring 2,000 content reviewers to ensure the Internet contents are safe to the community, and this news source reported that this social media company had recruited approximately 10,000 content reviewers in the past (Global Voices, 2017).

Voluntary industry self-regulation of the Internet industry works better when the threat of active enforcement of government regulations is present, and punishment for non-compliance is severe (Lee, 2002). Pre-emptive government regulation and government taking stern action to regulate the industry work as an incentive for the industry to enact self-regulation voluntarily. Active government participation in the self-regulation process of the Internet industry is very important in light of the large size of the industry, borderless cyberspace and absence of economic benefits directly attached to the self-regulation process. A strictly enforced government regulation motivates the Internet industry to actively engage with the government to ensure that self-regulation is adopted in such a way that there is a level-playing field for all companies, and they receive government assistance when needed.

Since the Internet's introduction to the Chinese population, the Chinese government has taken a proactive role in regulating the Internet industry for the nation's economic prosperity. It has actively monitored the industry, stepping in with stern enforcement of the regulations when required. Criticisms have arisen that this has curtailed the right to freedom of expression in the country. Some critics have accused the Chinese government of using Internet pornography regulation as an excuse to legitimise its political censorship. They have claimed that the government purposefully mixes pornography and political dissent in the same category of 'unhealthy' information in its campaigns against pornography (and other crimes) to take advantage of official rhetoric (Wu, 2009). Cyberspace is a tricky world with many contrasts. While the democratic world wishes this to be a space where freedom of expression prevails, there is an apprehension that freedom of expression may not suit children, generating a desire to at least control some Internet content through stringent laws. One argument is that governments can regulate the Internet with the greatest certainty by controlling its underlying code to create either 'a world of perfect freedom' or 'a world of perfect regulation' (Lessig, 1999). Absolute freedom of expression in cyberspace is a debatable 
outcome due to the contrasting nature of people accessing the Internet. In this kind of an environment, where one party can be a winner in cyberspace at another party's expense, with catastrophic outcomes like suicide, it can be argued that China's stringent policy to regulate the Internet industry might have benefited Chinese children directly or indirectly.

The Chinese government has used its active enforcement mechanisms and power to help the Chinese Internet industry genuinely self-regulate; something countries in other jurisdictions have been struggling to achieve. China has shown consistent effort and allocated the necessary resources and time to supervise the Internet industry to ensure that the industry carefully monitors Internet content to suit children. It has created an inbuilt stringent audit process to ensure that the quality of content is suitable for children. Specifically, pornography and other obscene content, and spam have received stringent regulation. China's approach to online pornography has some unique features. Unlike many Western countries, China has adopted a sweeping regulation over pornography and Internet games and denied its access to both adults and children. For example, Internet gaming companies such as Tencent Games were regulated to introduce an anti-gaming system which restricts children under 12 to play Internet game for only $1 \mathrm{~h}$ per day. Similarly, the media regulator ordered the permanent removal of Bytendance's joke because it promotes vulgur content among the community (Liu, 2018). The regulation goes to the extent of cleaning up the Internet, targeting not only pornographic material but also other indecent material the Chinese government defines as 'low and vulgar' (White Paper-The Internet in China, 2010).

In comparison to other nation's legal regulations, Bin and Lu (2012) argued that China's regulation of online sexual contents exhibits a number of unique features, including (a) a broad and sweeping definition of illegal pornography; (b) a lack of dissenting opinions; and (c) a unique campaign-style policing. The Chinese government has taken a proactive approach to combat the sexual contents in cyberspace, which makes it unique. The role played by China's famous Great Firewall in eliminating the sexual content from cyberspace to ensure child's wellbeing is a notable outcome in the fight to keep the Internet a safe space for children. China has built the most sophisticated, elaborate and extensive system that blocks content by preventing Internet Protocol addresses from being routed through standard firewall and proxy servers at Internet gateways (Chung, 2008). Empirical testing of China's Great Firewall has indicated that it is dynamic; it has been self-changing and refining over time, aiming at keeping the vast majority of citizens safe from unhealthy online material (O’Donnell \& Milner, 2007).

Another policy that has helped the Chinese Internet industry to effectively selfregulate is the Chinese government's active monitoring of information coming from countries other than China. This policy seems to have indirectly benefited children and protected them from the exploitation by international sex industry and criminal syndicates. This has not only helped domestic Chinese Internet companies to flourish but has also helped China develop its own Internet industry, which is financially better than those operating in other countries (Chen, Seong, $\&$ Woetzel, 2015). The creation of successful, locally grown Internet companies such as Baidu and QQ, which have stringent monitoring of Internet content, has 
benefited the Chinese children. The self-regulation process has helped the Chinese government to understand the Internet industry well and actively help it adhere to the government regulations. The vast numbers of networks linked to the Internet make it very difficult for the Internet industry and governments to ensure that every player adheres to the self-regulation principles. It is technically and realistically difficult to monitor and locate the violators of government policy in such an open, dynamic and interactive system. It is nearly impossible for the enforcement authority to identify the violators by relying on Internet users' responses as a way of supervising industry compliance. Users may not know when a violation of self-regulation occurs. In such a complex situation, the Chinese approach of strictly maintaining a China-specific cyber-territory can be argued as a highly practical, common-sense approach. The Chinse government and the ISC have developed a dual mechanism wherein the ISC, as the body representing the Internet industry in China, actively works with the government in enforcing government regulations while creating opportunities for Internet users to notify the Internet industry when inappropriate content appears on the Internet. China's policy on regulating the Internet industry has received wide support among younger generations in China (Yuan, 2018). The Chinese government has managed to create a mass national sentiment to support the government's fight to keep the Internet safe for children. These proactive and sustained efforts of the Chinese government are markedly different from other nations. To exercise control over the Internet, China has implemented statutory laws and administrative regulations through content filtering and user monitoring processes to maintain security and stability at both community and state levels. Regardless of critics, this model has proved to have the merits of effectiveness in the specific sociolegal context in the short term ( $\mathrm{Li}, 2015)$.

Due to the multi-layered nature of the Internet extending across the borders of all nations, China, like other nations, has its unique weaknesses and policy failures in managing the quality of Internet content. Xie, Qiao, and Wang (2016) argue that China has no systematic policy on prevention or intervention for child sexual abuse. China has focused too much on the Internet industry self-regulation, while paying less attention to educate the community regarding the issue such as child sexual abuse. Xie et al. (2016) observed that parents lack awareness about child sexual abuse and how to prevent it. China Daily (2018) suggests an urgent need for enactment of a specific law on cybersecurity for children to eliminate the new forms of violence against children. It argues that a legal provision should be created to allow people other than parents and children to file public litigation to protect children against online content to ensure children's safety in cyberspace. This report clearly highlights the importance of increased community consultation and involvement in protecting children online.

Community education and community involvement in the fight to keep children safe on the Internet are areas where the Chinese government seems to have focused less over the years. Probably due to the fear of creating negative political sentiments among Chinese communities and especially among online communities, the Chinese government might have gone too far to silence the 
community with harsh laws and punishments. In this process, the Chinese community might have lost its Good Samaritan spirit. Lee (2015) observes that China has a 'Good Samaritan's Dilemma' and suggests that the Chinese community urgently needs a legal framework, which is non-punitive and seeks to protect Good Samaritans which may encourage bystanders to be altruistic neighbours. By mobilising community participation, China can benefit a lot in its fight to keep the Chinese community safe in cyberspace. Involvement of the non-governmental community organisations working closely with the users of the Internet to educate them about the safe use of the Internet has seen minimal progress in China. Zhang and Guo (2012) observed that the Chinese government had not recognised the existence of non-governmental community organisations due to its apprehension of people assembling in the public sphere. Legget (2017) provides a good example of the crucial role played by the Chinese non-governmental organisations in creating community awareness regarding domestic violence and the rights of women. The crucial role of non-governmental organisations in empowering the Chinese communities to protect their children in cyberspace is an area long neglected by the Chinese government.

\section{Conclusion}

The present study on the Internet industry self-regulation of China has added depth to the subject matter under research. Certainly, this approach has provided different reference points on the subject of Internet industry self-regulation. It is interesting to note that the Chinese government has managed to consistently single out children in its fight against illegal elements in cyberspace. Unlike other governments, the Chinese government's consistency in policy formulation and strict enforcement and monitoring of the implementation of the policies, has helped it to achieve many milestones in the area of child protection in cyberspace. The analysis clearly suggested that governments have and need to play a critical role in developing and implementing a regulatory regime to curb harmful activities in the cyberspace to protect children; the government and Internet industry need to cultivate a constructive working relationship to uphold regulations; and that family, community and non-governmental organisations cannot be neglected in the Internet industry self-regulation process. For other countries, these are valuable lessons from the Chinese experiences of making the Internet a safe place for children.

\section{Declaration of Conflicting Interests}

The author declared no potential conflicts of interest with respect to the research, authorship and/or publication of this article.

\section{Funding}

The author received no financial support for the research, authorship and/or publication of this article. 


\section{ORCID iD}

Mubarak A. R. (ID https://orcid.org/0000-0002-9634-4056

\section{References}

Bin, L., \& Lu, H. (2012). Fighting the obscene, pornographic, and unhealthy-An analysis of the nature, extent, and regulation of China's online pornography within a global context. Crime and Social Change, 58, 111-130.

Budziewics-Guzlecka, A., \& Drab-Kurowska, A. (2018). Internet-selected aspects of threats for contemporary child on the example of Poland. In 28th International Scientific Conference on Economic and Social Development, Paris, 19-20 April 2018.

Chen, Y., Seong, J., \& Woetzel, J. (2015). China's rising Internet wave: Wired companies. McKinsey Quarterly. Retrieved from http://www.mckinsey.com/industries/high-tech/ our-insights/chinas-rising-Internet-wave-wired-companies.

Cheung, A. S. Y. (2006). The business of governance: China's legislation on content regulation in cyberspace. Retrieved from https://nyujilp.org/wp-content/uploads/ 2013/02/38.1_2-Cheung.pdf.

Chui, C., \& Jordan, L. (2018). Child protection in China: Threats and opportunities. Asia Pacific Journal of Social Work, 28(4), 1-13.

China Daily. (2018). Specific regulation needed for kids' online safety. Retrieved from http://www.chinadaily.com.cn/a/201801/25/WS5a694799a3106e7dcc13686f.htmlc.

Chung, J. (2008). Comparing online activities in China and South Korea. Asian Survey, XLVIII(5), 727-751.

Freedom on the Net. (2018). The rise of digitial authoritarianism. Retrieved from https:// freedomhouse.org/report/freedom-net/2018/rise-digital-authoritarianism.

Funnell, A. (2019). The Internet is dividing, and the choice boils down to China or the west. Australian Broadcasting Corporation. Retrieved from https://www.abc.net.au/ news/2019-05-23/Internet-dividing-choice-between-china-or-the-west/11130030.

Global Voices. (2017). China's Sina Weibo hires 1000 supervisors to censor 'harmful contents' - including women's legs. Global voices - Advox. Retrieved from https:// advox.globalvoices.org/2017/10/12/chinas-sina-weibo-hires-1000-supervisors-tocensor-harmful-content-including-womens-legs/.

Internet Society of China. (2009). Public pledge of self-regulation and professional ethics for China Internet industry. Retrieved from http://www.isc.org.cn/english/Specails/ Self-regulation/listinfo-15321.html.

Jing \& Chen. (2018). China fines Tencent, Baidu and Weibo over banned contents in ongoing crackdown. South China Morning Post. Retrieved from https://www.scmp. $\mathrm{com} /$ tech/china-tech/article/2112921/china-fines-tencent-baidu-and-weibo-overbanned-contents-ongoing.

Lee, Y. C. (2002). Internet privacy and electronic commerce: meeting the challenge of self-regulation in a digital environment ( $\mathrm{PhD}$ dissertation). Bloomington, IN: Indiana University.

Lee, M. Y. K. (2015). The role of law in addressing the good Samaritan's Dilemma: A Chinese model? Asian Journal of Law and Society, 2, 55-92.

Legget, A. (2017). Online civic engagement and the anti-domestic violence movement in China: Shifting norms and influencing law. Voluntas, 28, 2251-2277.

Leitch, S., \& Warren, M. (2015). Applying classification controls to Internet content in Australia. Journal of Information, Communication and Ethics in Society, 13(2), 82-97.

Lessig, L. (1999). Code and other laws of cyberspace. New York, NY: Basic Books. 
Li, X. (2015). Regulation of cyber space: An analysis of Chinese law on cyber crime. International Journal of Cyber Criminology, 9(2), 185-204.

Liu, J. (2018). China Internet report 2018: Chinese Internet giants are expanding and so is government regulation. Retrieevd from http://chinafilminsider.com/china-Internetreport-2018-chinese-Internet-giants-are-expanding-and-so-is-government-regulation/.

Livingstone, S., Haddon, L., Gorzig, A., \& Olafsson, K. (2011). Final report, EU Kids online II. London, UK: LSE.

Li-xian, C. O. N. G. (2008). Copyright infringement liability of Internet service provider. Present Day Law Science, 1.

Low, B. (2010). An institutional and network perspective of organizational legitimacy: Empirical evidence from China's telecommunications market. Asian Academy of Management Journal, 15(2), 117-134.

Lyombe, E., Kumar, A., \& Qingjiang, Y. (2011). Google this: The Great Wall of China, the IT Wheel of India, Google Inc and Internet regulation. Journal of Internet Law, 15(3), 3-4.

Marsden, C. T. (2011). Internet co-regulation-European law, regulatory governance and legitimacy in cyberspace. Cambridge University Press. doi:https://doi.org/10.1017/ CBO9780511763410.

Mueller, M., Mathiason, J., \& Klein, H. (2007). The Internet and global governance: Principles and norms for a new regime. Global Governance, 13(2), 237-254.

O'Donnell, I., \& Milner, C. (2007). Child pornography: Crime, computer and society. Collumpton, UK: Willan Publishing.

OECD. (2012). The protection of children online-Recommendation of the OECD Council - Report on risks faced by children online and policies to protect them. Retrieved from https://www.oecd.org/sti/ieconomy/childrenonline_with_cover.pdf.

Pinghui, Z. (2019). China moves to strengthen child protection laws with measures to help those at risk of abuse and cyberbullying. South China Morning Post. Retrieved from https:/www.scmp.com/news/china/society/article/3034083/china-moves-strengthenchild-protection-laws-measures-help-those.

Tao, Q. (2014). Legal framework of online intermediaries' liability in China. The Journal of Policy, Regulation and Strategy for Telecommunications, Information and Media, 14(6), 59-72.

United Nations. (2005). Report of the working group on Internet governance. Retrieved from https://www.wgig.org/docs/WGIGREPORT.pdf.

Vartanova, E. L., Tolokonnikova, A. V., \& Cherevko, T. S. (2014). The information security of children: Self-regulatory approaches. Psychology in Russia, 7(3), 136-145.

White Paper-The Internet in China. (2010, June 8). The Information Office of the State Council of the People's Republic of China or China's Cabinet. Retrieved from http:// www.gov.cn/english/2010-06/08/content_1622956.htm.

Wu, G. (2009). In the name of good governance: E-government, Internet pornography and political censorship in China. In X. Zhang \& Y. Zheng (Eds.), China's information and communications technology revolution: Social changes and state responses (Chap. 4, pp. 68-85). New York, NY: Routledge.

Xie, Q. W., Qiao, D. P., \& Wang, X. L. (2016). Parent-involved prevention of child sexual abuse: A qualitative exploration of parent's perceptions and practices in Beijing. Journal of Child and Family Studies, 25, 999-1010.

Ying. \& Gao vs sinoi.com. (2002). Haidian people's court. Beijing (2002). HMCZ-742.

Yuan, L. (2018). Young people in China don't know the Internet we do - and they like it that way. Independent New Paper. Retrieved from https://www.independent.co.uk/life- 
style/gadgets-and-tech/features/china-Internet-social-media-great-firewall-of-chinacensorship-apps-a8510036.html.

Zhang, Z., \& Guo, C. (2012). Advocacy by Chinese non-profit organisations: Towards a responsive government? The Australian Journal of Public Administration, 71(2), 221-232. 